\title{
Green Strength Optimization in Metal Injection Molding applicable with a Taguchi Method L9 (3)
}

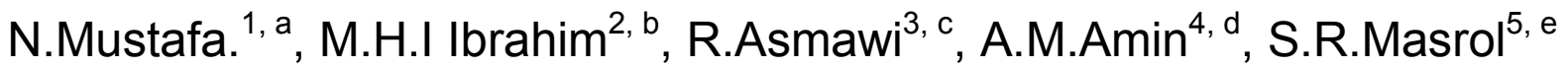 \\ ${ }^{1}$ Advanced Manufacturing and Material Center (AMMC) \\ ${ }^{2}$ Faculty of Mechanical and Manufacturing Engineering \\ Universiti Tun Hussein Onn Malaysia \\ anj.wawa@gmail.com, ${ }^{b}$ Mdhalim@uthm.edu.my, ${ }^{c}$ roslias@uthm.edu.my, dazriszul@uthm.edu.my, \\ esrizal@uthm.edu.my
}

Keywords: S/N ratio, Metal Injection Molding, Strength Optimization,

\begin{abstract}
Recently Metal injection molding is selected as a vital process in producing large amount of small part with complex geometry and intricate shape. This process is lead to solve cost effective issue in manufacturing fields. Feedstock composition behavior categorized as one of impact factor in determines the victories in metal injection molding process. Thus this paper is focused on optimizing the strength of green part by applied Taguchi Method L9 $\left(3^{4}\right)$ as optimization tools during injection process. The composition of feedstock is $55 \%$ powder loading (PL) were injected by injection molding machine .Several injection parameter were optimized such as injection temperature (A), barrel temperature (B), injection pressure (C) and Speed (D) The results analyzed by using Signal to Noise Ratio ( $\mathrm{S} / \mathrm{N}$ ratio) terms. The highest green strength is $\mathrm{A}_{2}, \mathrm{~B}_{2}, \mathrm{C}_{2}$, and $\mathrm{D}_{2}$
\end{abstract}

\section{Introduction}

Metal injection Molding(MIM) is referred to the manufacturing technology that explored due to mass production of green part with intricate size, complex shapes and geometry. This technology are based on injection molding but respect to focus on metal powder [1]Currently the areas of application can be applied in the biochemical, aerospace, computer peripherals and automobile industries. In MIM, binder systems play an important role as it acts as a temporary vehicle as homogeneously factor in order to packing the powder into the desired shape [2] The green strength means the mechanical strength of parts where as a compacted powder compacted powder must have in order to withstand mechanical operations and it is subjected after pressing and before sintering, without damaging its fine details and sharp edges [3] The objective of this paper is to evaluate the strength of green part from MIM process before it's undergoes to debinding or sintering process based on the different composition ratio between waste garbage bag, Palm Kernel and Stainless Steel 316L

\section{Methodology}

Materials. In this research the material that acted as metal powder are known as SS316L stainless steel water atomised powder (Epson Atmix Corp) with irregular shapes as it is compatible with water leaching and high corrosion resistance. Moreover the SS316L with garbage bag from the HDPE group were mixed up together and then added up the palm kernel by mixing process due to produce a feedstock for injection process.

Significantly, the selected of garbage gag (HDPE) as a primary binder system is due to support an affords towards green technology in reduce the environmental pollution issue. While the uses of palm kernel as an exploration contribution of new binder system in metal injection molding. The characteristic of SS316L are presented in Table 1[3] while Table 2 exhibit the properties of binder used in this study 
Table 1: Stainless Steel (SS316L) powder characteristics [3]

\begin{tabular}{ll}
\hline Characteristic & Details \\
\hline Identification & SS31L PF-10F \\
Powder Source & Epson Atomix Corp \\
Tap density $\mathrm{g} / \mathrm{m}^{3}$ & 4.06 \\
True pynometer density $\mathrm{g} / \mathrm{m}^{3}$ & 8.0471 \\
Powder size & $\mathrm{D} 10=2.87 \mu \mathrm{m}$ \\
& $\mathrm{D} 50=5.96 \mu \mathrm{m}$ \\
& $\mathrm{D} 90=10.65 \mu \mathrm{m}$ \\
\hline
\end{tabular}

Table 2: Binder Properties

\begin{tabular}{|c|c|c|c|c|c|}
\hline Binder & Type & Designation & $\begin{array}{c}\text { Melting } \\
\text { Temperature }{ }^{\circ} \mathrm{C}\end{array}$ & $\begin{array}{c}\text { Degradation } \\
\text { Temperature }{ }^{\circ} \mathrm{C}\end{array}$ & Density $\mathrm{g} / \mathrm{m}^{3}$ \\
\hline Binder 1 & Primary & $\begin{array}{c}\text { Garbage bag } \\
\text { (HDPE) }\end{array}$ & $100.4{ }^{\circ} \mathrm{C}$. & $456.1{ }^{\circ} \mathrm{C}$ & 0.9048 \\
\hline Binder 2 & Secondary & Palm Kernel & - & $404.7^{\circ} \mathrm{C}$ & 0.8915 \\
\hline
\end{tabular}

Taguchi Method Artogonal Array L9 $\mathbf{( 3}^{\mathbf{4}}$ ). The strength optimization was conducted by implementation of Taguchi Arthogonal Array (Statistical Method). The injection process was run in 3 level design of experiment with 4 parameters and 9 trial of experiment. The parameters that involved are injection temperature (A), barrel temperature (B), injection pressure (C) and Speed (D). Moreover the adjustment of injection parameter in smart rules could retrieved the best performance sample where as by maximize or minimize the characteristic [4]. The results analyzed by using Signal to Noise Ratio ( $\mathrm{S} / \mathrm{N}$ ratio) terms

In detailed explanation, $\mathrm{S} / \mathrm{N}$ ratios is help in prediction the optimum result besides improve the quality via variability reduction and improved the measurement based on repetition [4]. Thus, paper are discussed the optimization of highest green strength with 0.55 Powder loading. The analysis are based on Signal to noise ratio or well known as $\mathrm{S} / \mathrm{N}$ ratio. This analysis are based on Larger is better characteristic.

\section{Results and Discussions}

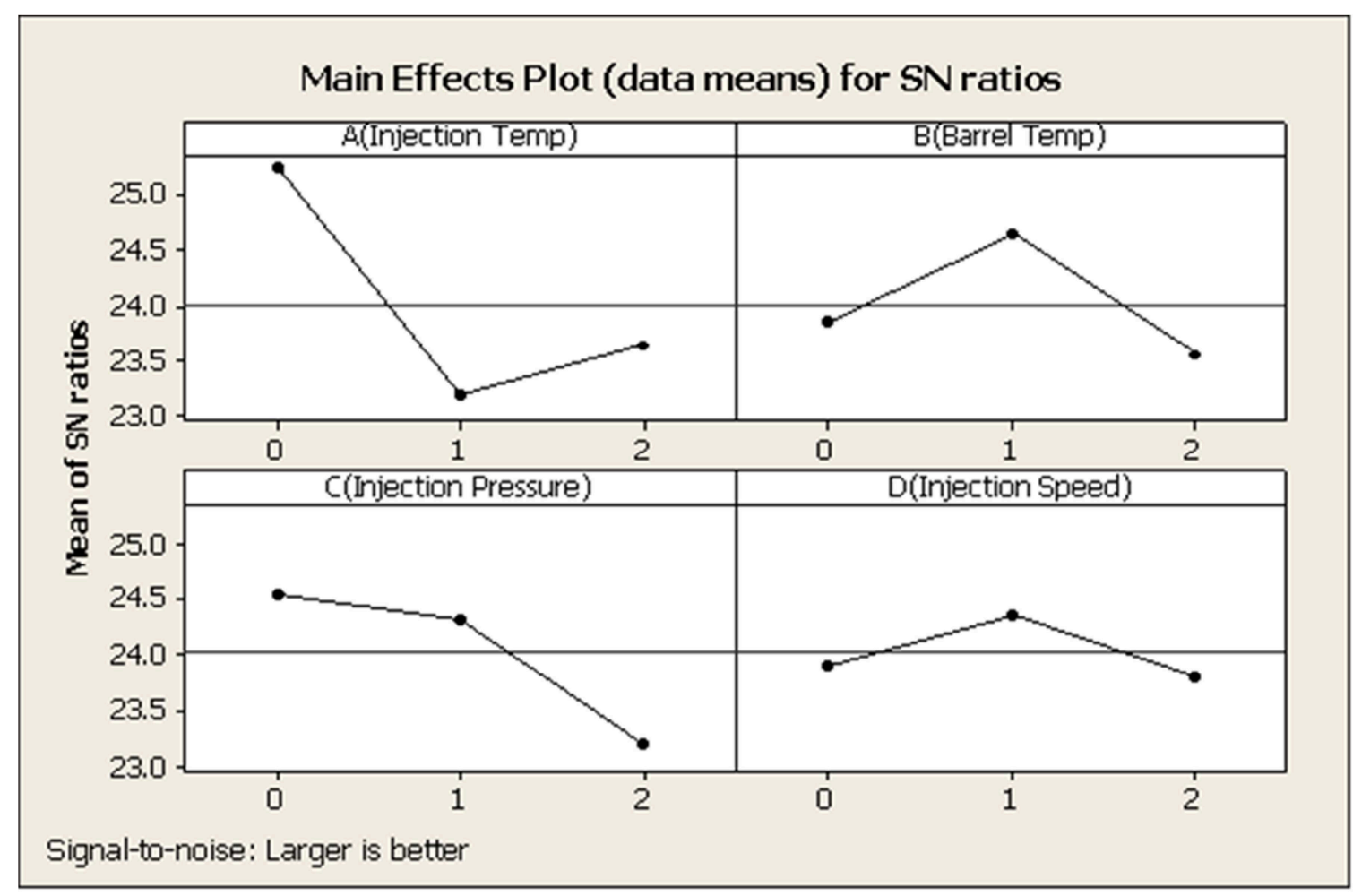

Figure 1: Main effect plot (data means ) Signal To Noise Ratio of 0.55 powder loading 
By referring the figure 1 above, the optimize variable of higher green strength for injection part with powder loading 0.55 were obtained. The green strength of injection part is needed to optimize in order to determine the best part with higher green strength and could accommodate a load when subjected to the part. The graph predicted that the best optimum variable is $A_{0}, B_{1}, C_{1}$ and $\mathrm{D}_{1}$ or in other words the injection temperature $185{ }^{\circ} \mathrm{C}$, barrel temperature $190{ }^{\circ} \mathrm{C}$, injection pressure $11 \mathrm{Mpa}$, and speed $90 \%$. The result supported by Ibrahim et al [4] where as temperature and pressure give the best effect of variable in determine the highest green strength. By using this Taguchi method orthogonal array it can be reduce the cost effectively.

\section{Conclussions}

The optimization of injection variable in determination the highest green strength part have been done successfully by the implementation of Taguchi Method L9 $\left(3^{4}\right)$. The optimum variables are defined based on larger is better characteristic. The highest green strength is $A_{2}, B_{2}, C_{2}$, and $D_{2}$. The variables (A )stand for injection temperature while (B) barrel temperature, injection pressure (C) and Speed (D)Taguchi Method is established as one of the best method in optimizing the injection variables as it can reduce the cost, time, improve accuracy and efficiency. The aims of this paper where as to determine the optimum injection variables have been done successfully

\section{References}

[1] German.R and Bose Injection Molding of Metals and Ceramics Metal. Powder Industries Federation U.S.A (1997)

[2] Z.Y. Liu , N.H. Loh , S.B. Tor , K.A. Khor , Y. Murakoshi , R. Maeda Mixing and characterisation of $316 \mathrm{~L}$ stainless steel feedstock for micro powder injection molding Materials Characterization 54 (2005) 230- 238

[3] M.H.I. Ibrahim, N. Muhamad, A.B. Sulong, K.R. Jamaludin, S. Ahmad and N.H.M. Nor Optimization of Micro Metal Injection Molding For Highest Green Strength by Using Taguchi Method International Journal of Mechanical and Materials Engineering (IJMME), Vol. 5 (2010), No.2, 282-289

[4] M.H.I. Ibrahim, N. Muhamad, A.B. Sulong, K.R. Jamaludin, S. Ahmad and N.H.M. Nor Single Performance Optimization of Micro Metal Injection Molding for the Highest Green Strength by Using Taguchi Method International Journal of Integrated Engineering (Issue on Mechanical, Materials and Manufacturing Engineering (2010) 